\title{
Transatlantica
}

Revue d'études américaines. American Studies Journal

\section{Demons of Chance, Angels of Probability: Thomas Pynchon's Novels and the Philosophy of Chance and Probability}

\section{Arkady Plotnitsky}

\section{(2) OpenEdition}

Electronic version

URL: https://journals.openedition.org/transatlantica/15498

DOI: 10.4000/transatlantica.15498

ISSN: 1765-2766

Publisher

Association française d'Etudes Américaines (AFEA)

Electronic reference

Arkady Plotnitsky, "Demons of Chance, Angels of Probability: Thomas Pynchon's Novels and the Philosophy of Chance and Probability", Transatlantica [Online], 1 | 2020, Online since 01 December 2020, connection on 02 February 2023. URL: http://journals.openedition.org/transatlantica/15498 DOI: https://doi.org/10.4000/transatlantica.15498

This text was automatically generated on 2 February 2023

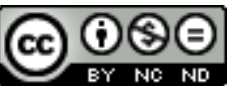

Creative Commons - Attribution-NonCommercial-NoDerivatives 4.0 International - CC BY-NC-ND 4.0 https://creativecommons.org/licenses/by-nc-nd/4.0/ 


\title{
Demons of Chance, Angels of Probability: Thomas Pynchon's Novels and the Philosophy of Chance and Probability
}

\author{
Arkady Plotnitsky
}

\section{An Introduction: Reality without Realism, Probability without Causality, and Multiplicity without Unity in Physics and Literature}

1 This article considers the relationships between Thomas Pynchon's novels and the philosophy of chance and probability, especially in connection with quantum theory, which radically transformed our thinking concerning both concepts and, in the first place, the nature of physical reality and our interaction with it. From early modernist authors, such as Franz Kafka, James Joyce, Virginia Woolf, and Samuel Beckett, until our own time, literature has responded to this transformation and its implications. Such responses need not overtly engage with quantum theory. Indeed, they, or literary responses to other mathematical and scientific theories, are sometimes more effective when they use mathematical and scientific ideas translated into more general terms, dealing with one or another area of human life, even when their engagement with mathematics and science is more pronounced, as it is in Pynchon's work. It is this type of response to quantum theory and the role of chance and probability there that is my main concern in this article, rather than Pynchon's explicit links to quantum theory or other theories dealing with chance and probability. I shall discuss such links as well, but primarily as part of Pynchon's broader engagement with these theories in order to relate his literature to human life in new ways. This use of mathematics and science in literature is, thus, conceptual and, in this sense, philosophical, keeping in mind that the main means of this use are still literary. Textual and conceptual elements embodying 
these connections are products of the compositional architecture of his novels, rather than conventionally philosophical, although, as discussed below, this distinction is not unconditional, because philosophy or mathematics and science have compositional dimensions to them too. Accordingly, although this introduction primarily aims at presenting the philosophical content of the mathematical and scientific theories in question, it will also comment, in a preliminary fashion, on Pynchon's compositional integration of them, discussed in detail in the remainder of the article.

2 I begin with considering the difference, not always sufficiently appreciated, between chance and probability. While chance and its avatars, such as randomness, uncertainty, or indeterminacy, or (their categorical opposite) causality have been extensively considered in commentaries on Pynchon, probability has received significantly less attention, often because of the unexamined use of probability as a different category. This is not surprising, because this is also the case in literary studies in general. Chance and its avatars just mentioned can be defined differently as well, but they are close to each other in most definitions, and can be treated mostly interchangeably for the purposes of this article. For convenience, I shall primarily speak of randomness or chance. Randomness or chance is a manifestation of the unpredictable, as concerns either future events or events that have already happened but were unexpected, even though both types of events might have hidden causes and thus are in fact not random. By its unpredictability, randomness or chance brings an element of chaos into our interactions with the world. By contrast, the use of probability, which has to do with our estimates, sometimes numerical, concerning the likelihood of events, allows us to restore a degree of order in dealing with situations in which chance plays a shaping role. Probability is, thus, related to the interplay of chaos and order. It is "chaosmic," in James Joyce's famous coinage, possibly influenced by quantum theory, where the term may be more fitting than in classical physics, particularly chaos theory, in describing which the term has been used (Joyce 2012, 118, 149).

When this interplay is found in classical physics, from Galileo on, or in most philosophy, from Plato on, it is assumed to be ultimately underlaid by an order defined by causality. A causal order connects all events considered by a law or set of laws and makes chance and probability merely a practical, epistemological matter, due to our inability to access this order. In dealing with simpler (nonchaotic) causal systems considered in classical mechanics, chance could be avoided altogether, at least ideally, and our predictions concerning their behavior could be ideally exact, deterministic. By determinism, I shall refer, epistemologically, to the possibility, at least ideally, of such exact predictions, in contrast to causality, which refers, ontologically, to the behavior of physical or other objects considered. While both classical statistical physics and chaos theory are, ontologically, causal, they are not, epistemologically, deterministic, because the mechanical complexity of the systems they consider makes the recourse to probability unavoidable in predicting their behavior. Thus, the "chaosmos" of classical physics, even chaos theory, is merely a practical, epistemological matter, and hardly merits the name.

4 The case is fundamentally different in quantum theory, specifically in quantum mechanics, QM, discovered by Werner Heisenberg in 1925 and, independently, by Erwin Schrödinger in 1926, and still the standard form of quantum theory in low energy regimes. High-energy regimes are handled by quantum field theory, QFT, which is similar to and even more radical than QM in those of its aspects that are pertinent to 
this article. While QM is indeterministic regardless of interpretation, there, at least in certain interpretations, beginning with that of Niels Bohr, the recourse to probability is due to a lack of an underlying causal order at the ultimate level and even to the impossibility of assuming it, rather than the difficulties or impossibility of accessing this order. ${ }^{1}$ The impossibility of this assumption defines the concept "reality without realism," RWR, introduced by this author previously (e.g., Plotnitsky 2016, Plotnitsky and Khrennikov 2015). This concept only assumes, in affinity with Jacques Lacan's concept of the Real (which Lacan relates to chance as well), the concept of reality, defined as something that is assumed to exist, while placing the character of this existence beyond representation or knowledge, or even conception. In the latter case I shall speak of "the strong RWR view." ${ }^{2}$ The RWR view should not, however, be seen as assuming a form of undifferentiated Oneness, albeit beyond knowledge or thought. As discussed below, the reality in question is each time different, even as it is each time inconceivable, a difference that is manifested in its different effects. "Realism" is defined by assuming the possibility of at least such a conception and usually a representation of the reality considered by a theory. Indeed, an undifferentiated Oneness is a conception of reality.

5 As beyond thought, the ultimate nature of reality at stake in QM cannot be assumed to be random either, any more than causal. Nor can it be assumed to be defined by any combination of chance and causality, or order and chaos, unless one uses the term "chaos," following one of its ancient Greek senses (areton or alogon), as referring to that which is beyond all comprehension. QM, in RWR-type interpretations, is chaosmic because of the chaosmic nature of effects the Real, usually idealized as quantum objects, has on the world we observe by means of and in experimental technology, as manifested in quantum phenomena, defined by such observation. Murray Gell-Mann famously borrowed the term "quark" from Finnegans Wake (Joyce, 2012 118). Joyce's masterpiece, originally published in 1939, was, however, itself influenced by quantum theory, not inconceivably by the discovery of antimatter, which was widely discussed at the time, just as the Higgs boson or black holes are now (Joyce, 2012 383, 149). As he said in Finnegans Wake, clearly referring to the nature of the novel itself, "I am working out a quantum theory about it for it is really most tantalizing state of affairs" (Joyce 2012, 149). In the novel words transform into each other just as particles do in highenergy quantum physics and quantum field theory, QFT. The word "chaosmos" is an example of such a transformation. As will be seen, Pynchon adopts this technique, especially in constructing the signifiers of proper names.

Quantum phenomena and, hence, QM are not defined by chance alone. For one thing, if quantum events were purely random events, it would make it impossible to treat them scientifically, which requires at least the use of probability, so the probabilistic predictions of QM could be verified. As I said, in contrast to classical physics, the probabilistic order found in quantum physics does not appear to, and in RWR-type interpretations does not, arise from an underlying causal order. Instead, it emerges only at the level of quantum phenomena or events, as effects of the Real, which is beyond order and chaos alike. This order is, moreover, very special because of the existence of the so-called quantum correlations (not found in classical physics) between certain sets of quantum events, while each individual event involved is random. Indeed, that, in certain circumstances, random individual events can combine to form a statistically correlated order, in the absence of an underlying causal order, is one of the greatest mysteries of quantum physics. While the existence of an underlying causal 
order cannot be excluded, assuming it poses difficulties in the case of quantum correlations. As will be seen, correlations echoing quantum correlations, "the Slothrop correlations," as I shall call them, and the question of how they come about define the set-up of Gravity's Rainbow.

Beginning with V. (Pynchon 1961) and The Crying of Lot 49 (Pynchon 1966), or earlier short stories, such as "Entropy" (1960), Pynchon's works engage with most known, in fact just about all (as there are not that many), conceptions of chance and probability, and physical theories that involve them, such as thermodynamics, quantum theory, and chaos theory. Three demons of chance in physics figure in Pynchon's work, one of which, Maxwell's demon, is expressly invoked in The Crying of Lot 49. Laplace's demon, which allows one to represent the ultimate causality behind chance, and thus is more akin to the angel of causality, which governs all classical physics or relativity; Maxwell's demon in thermodynamics, which, as part of classical statistical physics, complicates the nature of this causality, while still preserving it; and Heisenberg's demon invoked, by analogy with the two others, by Gilles Deleuze and Félix Guattari (1994 129), in the context of Heisenberg's uncertainty relations, $\Delta q \Delta p \quad h$ (where $q$ is a coordinate, $p$ is a momentum in the direction of $q, \Delta$ is the standard statistical deviation, and $h$ is a Planck constant). The uncertainty relations prevent us from simultaneously assigning to a quantum object both an exact position and an exact momentum, always possible in classical mechanics and assuring causality there. Importantly, the uncertainty relations are not about the lack of sufficient precision of our instruments. They would remain valid even if we had perfect instruments. In the RWR view, the uncertainty relations are correlative to the fact that one cannot assume causality underlying chance, or a conception of the ultimate nature of reality responsible for quantum phenomena. Luckily, the angel of probability is on our side, enabling us to correctly predict the probabilities of quantum events by using QM or, in high-energy regimes, QFT.

Adding an intriguing twist, these theories are sometimes invoked by and even encoded in characters' names, beginning with Dudley Eigenvalue in V. (Pynchon, 1961). "Eigenvalue" is a key term in the mathematical formalism of QM and related mathematical theories, the use of which in QM, as will be seen, is brought to bear on Pynchon's narrative in $V$. This concept, as a mathematical concept, also figures significantly in Against the Day (e.g., Berressem 2018). The use of mathematical and scientific signifiers as proper names (which need not be names of characters) is effective, both as a literary play and as the technology of delivering the philosophical import of mathematical and scientific theories. There are many other ways, some discussed below, in which Pynchon's novels do both; and a great deal of good scholarly commentary has been devoted to their engagements with mathematical and scientific theories, including QM. This article, again, pursues a different project, which concerns how Pynchon's novel adopts the key philosophical aspects of QM, "abstracting" them from $\mathrm{QM}$, in exploring the "QM-like" complexities of human life. ${ }^{3}$ As stated from the outset, even if one bypasses Pynchon's manifested engagements with elements of QM, one could still argue this case, just as one could argue for the "QM-like" character of Finnegans Wake, even if Joyce did not expressly mention quantum theory. In both cases, invoking quantum theory is more a symptom or a "sinthome" in Lacan's sense (here as something inscribed in the process of a literary work) of what is ultimately at stake, 
which concerns human life, rather than QM (Lacan 2016). In other words, such works are philosophically QM-like, regardless of their overt invocations of QM.

While Pynchon's novels take advantage of the physics, classical and quantum, of chance and probability, they do not appear to be ultimately advocating a definitive philosophical position on the subject, even within each work. Indeed, although such assessments are unavoidably conjectural, probabilistic, one might argue for a degree of ambivalence toward the radical, RWR-type view and some preference for a more classical view of chance and probability, at least at certain junctures of his works. This is not unexpected. Very few accept, especially as the last word on this subject, this character, defined by Heisenberg's thinking leading him to his discovery of QM and then Bohr's interpretation of it. ${ }^{4}$ A realist understanding, firmly established in science by the nineteenth century-as represented in particular by Pierre-Simon Laplace's vision of the world-has continued to persist and remain dominant. This dominance is exemplified by Einstein's famous discontent with QM, a discontent most widely known by his repeated pronouncements to the effect that "God doesn't play dice" (e.g., Born 2005 , 88). Einstein's ultimate concern was with the lack of realism in QM rather than only with chance and probability. Realizing, however, that the lack of realism makes probability unavoidable, Einstein also preferred causality at the fundamental level and a theory of quantum phenomena that would be ideally deterministic, just as relativity was. (No determinism other than ideal is possible in physics.) As QM and its extension to high-energy quantum physics, QFT, remain our standard theories of quantum phenomena, nearly a century after this assessment, the debate has continued with undiminished intensity and is ongoing.

The philosophical and sometimes practical, including political, stakes in this debate are enormous, and they extend far beyond physics. One deals with the confrontation between two fundamentally different views of the world, or two ontological hypotheses, realist and RWR-type. The first assumes the ultimate causal order underlaying chance and the second in principle precludes this assumption, at the ultimate level of reality, making it RWR-type. While it may be intriguing that physics, in the form of quantum theory, has presented us with this alternative, the situation would not be different philosophically even if quantum theory had proven to be classical-like, or if a future theory that might replace QM might as yet be proven to be.

11 Suppose something has happened: let us call it an "event," like that of "Oedipa, [having] been named executor, or she supposed executrix, of the estate of one Pierce Inverarity, a California real estate mogul" (Pynchon 1966, 9). How did it come about? Something must have caused it, or so it would appear and so it is generally assumed, especially if the event belongs to an ordered configuration or arises according to some law. Kant calls this assumption the principle of causality. He defines that which causes an event as its cause (which may be multiple) and the event itself as an effect of this cause (Kant 1997, 305, 308). Causality proceeds from causes to effects, while the principle of causality proceeds, by inference, from effects to causes. The principle of causality implies that reality has a causal character. The question becomes whether one can conceive of this character, define it, describe it, and so forth, in short, whether this character allows for a realist treatment. This is known as the problem of causality, astutely understood by David Hume. It is, Hume contended, beyond our reach ever to ascertain real causal connections between events, even if they exist; we can at most surmise probable connections between events, although in certain cases such 
connections appear to be nearly certain. Nevertheless, one might still reason as follows, as Oedipa in effect does in The Crying of Lot 49. While such ultimate causal connections between events and the architecture of the underlying reality (responsible for these connections) may be unknowable for us, they, as against the strong RWR view, may, in principle, be thinkable, conceivable by us, even if without certainty as to whether such conceptions are correct (Kant 1997, 115). At the very least, one can assume, as both Kant and Hume did, that there is an order, natural or divine, defining the ultimate nature of reality. This is the most general form of the view of the world or ontological hypothesis that I call realism. This view has a spectrum of more specific instantiations, not all of which are causal, although most are. Several are found in Pynchon's novels. Two examples, discussed below, are Oedipa's assumption that Pierce's estate has an ultimate underlying organization that she needs to figure out, and the Pavlovian determinism of Edward Pointsman in considering Tyrone Slothrop's case in Gravity's Rainbow.

12 The reality without realism, RWR, ontological hypothesis, while it assumes that the world exists, is real, rejects the applicability of the principle of causality and, even more fundamentally, the assumption that one could represent or even conceive of the ultimate constitution of this reality, making it RWR. While there are earlier intimations of this view, it may be argued to have emerged as such with Heisenberg's discovery of QM and Bohr's interpretations of it. As noted above, the situation becomes especially enigmatic, even mysterious, because of the probabilistic order, that of correlations, found in quantum phenomena. The deepest mystery of quantum physics is its order. Where does this quantum order come from, while all individual events considered are random? An underlying classical-like causal order would provide an answer. It is, however, not compatible with this order, which it is not, as reflected by the so-called Bell and Kochen-Specker theorems. The RWR answer is that we do not or, more radically, cannot know or even conceive of how this order, or quantum randomness, comes about. They are effects of that which is neither ordered nor random, any more than anything else. There is no story to be told and no concept to be formed concerning the processes that lead to this order or this randomness. Fortunately, we are, again, saved by the angels of probability, probability without causality, at least in QM, which predicts these effects strictly in accord with what is observed.

13 I close this introduction by considering the RWR view of multiplicity. Multiplicity has been arguably the most prominent concept in recent ("postmodernist") theoretical discussions and literary criticism. Just as in the case of chance and probability, the question is: what is the nature of the multiple involved, what kind of concept of the multiple must one adopt given the situation confronted? There have been instances of denying the possibility of applying the idea of multiplicity to the ultimate level of existence, beginning with Parmenides's concept of the One, as defining the ultimate reality of things, a view adopted by Plato. Multiplicity, or difference and change or becoming (which would be equally subsumed by the One), were seen as illusions of the human senses to be overcome by philosophical thought. The idea has never died, and it is sporadically invoked in contemporary physics (e.g., Barbour 1999). However, from the pre-Socratics to Heidegger and beyond, it is not the undifferentiated Oneness that was primarily at stake in understanding nature and thought but how the play of difference, multiplicity, or change are governed by one or another form of order and containable accordingly. 
14 Alternatively, one might contemplate, in Alain Badiou's language, the multiple-withoutOne, a form of multiplicity that cannot be subsumed by either a unity or a containable multiplicity (Badiou 2007, 29). Then the question becomes whether the multiplewithout-One is only epistemological or is ontological, whether it reflects the plurality of thinking and knowledge concerning a single world, or the plurality of worlds themselves, or both, multiple worlds and multiple ways of thinking and knowledge concerning each. It can also be an effect of that which is neither multiple nor single, as in the RWR view, when the irreducibly multiple is defined by effects of the irreducibly unthinkable, which, it follows, is each time different, even if each time unthinkable. In quantum theory, this irreducibly multiple came into the forefront with high-energy physics and QFT, beginning with the discovery of antimatter, by Paul Dirac, which, in RWR-type interpretations, added the irreducibly multiple to the irreducibly unthinkable of QM. QFT had a notable impact on Pynchon's novels, both expressly, as in Vineland, and in terms of the multiplicity of the signifying play, akin to that in Joyce's Finnegans Wake, throughout.

There are other concepts of the multiple in contemporary physics, including ontological ones. In physics, from the ultimate microscopic constitution of nature to cosmology, it is more natural to think of a single world. On the other hand, the idea of co-existing parallel worlds has been entertained at least since Gottfried Leibniz, who, however, thought in terms of compossible, rather than coexisting, worlds. The ideas acquired a new prominence in recent decades. One of the main reasons is the so-called "many worlds interpretation" of QM. It was introduced by Hugh Everett in 1957, as a response, on realist and causal lines, to the radical nature of QM, especially in RWRtype interpretations. Everett's scheme does not contain either the irreducibly unrepresentable (or unthinkable) or the irreducible chance or probability at the ultimate level of reality. Both are brought about by our limited, one-world experience of the many-worlds reality. This interpretation has remained controversial, not the least because of its nonfalsifiable nature. It has, however, acquired more prominence recently, helped by other many-worlds or "multiverse" conceptions, introduced in conjunction with cosmology (e.g., Carroll 2019). All these conceptions remain controversial, in part, again, because of the difficulties or even impossibility of falsifying them, even in principle, by any available or even conceivable data.

Literature allows for a much freer experimentation with multiple worlds or ontologies. Brian McHale sees this experimentation as characterizing postmodern literature, with Pynchon's Gravity's Rainbow (Pynchon, 1973) as a paradigmatic example, vis-à-vis modernist literature, defined by experimenting with epistemological pluralities of thinking concerning a single world (McHale). While one might argue that the situation and the borderlines between postmodernist and modernist literature are more complex in this regard, it would be difficult to deny that Pynchon's works are marked by their experimentation with multiple ontologies. Their relationship to the many worlds interpretation of $\mathrm{QM}$ and related theories just mentioned is a more complex matter. Thus, Pynchon's experimentation with ontologies in Gravity's Rainbow appears to be independent of them. On the other hand, Everett's interpretation appears to have influenced the narrative structure of Mason \& Dixon, although one could still read this structure on lines of QM or QFT, without appealing to many worlds. Multiple narratives in question would, then, refer to different ways in which things might have happened in a single world, rather than different ways in which they had happened in different worlds. 
17 In sum, the RWR view, in quantum theory and beyond, is interactively defined by: 1) the irreducible unthinkable in thought; 2) the irreducible multiple; and 3) irreducible chance and probability, as the irreducible interplay of chaos and order. The irreducible nature of each is crucial because the multiple, the unthinkable, and chance and probability are also found, and are important in classical thinking, but there they are seen as ultimately reducible, at least in principle, to unity, accessibility to thought (which makes it more accurate to speak of the as-yet-unthought rather than the unthinkable), and causality, although not necessarily to determinism. The RWR view changes the character of thinking and knowledge. They include the assumption that there is something that is beyond knowledge or even thought, now or possibly ever, while at the same time being responsible for what we can think or know. To handle these effects, one needed new theories, and one will continue to need them to advance physics, just as one needs new literary or artistic compositions to have new literature and art, or new concepts to have new philosophy. The RWR may be necessary to advance thinking and knowledge, but it is never sufficient to do so. Heisenberg's discovery of QM and Pynchon's literary works are only two examples, albeit remarkable ones, of the necessity of, as it may be called, following Deleuze and Guattari, compositional thinking $(1994,163-200)$. It is true that they only apply this concept to art. I would maintain, however, that it is extendable to creative thinking in mathematics and science, or philosophy. ${ }^{5}$ Thus, Heisenberg's thinking was compositional. In his hands, QM was defined by how its key elements were related to each other within the structure of the theory in order to predict the probabilities of the outcome of quantum experiments, without representing how these outcomes come about. While, however, its RWR nature might highlight the compositional nature of a theory as invented by Heisenberg, just as an abstract painting may highlight it in art, it does not define this nature. Einstein's thinking that led him to relativity or Schrödinger's thinking that led him to the co-invention of QM was compositional while governed by realist principles. This brings these figures and Pynchon, and, with them, physics and literature, together not only on philosophical grounds, defined by the nature of physical theories in question, but also on literary grounds, defined by the art of composition.

\section{V-Variations, from $V$. to Vineland}

With his first novel, V., Pynchon continues his engagement with, and thinking through the philosophical implications of, quantum physics begun in his earlier short stories. "V" itself is a famously persistent signifier in Pynchon's titles, V., GraVity's RainboW, Vineland, and Inherent Vice. It is inserted in multiple signifying chains, some of which are mathematical or physical. Thus, V stands for "vector," a key concept in mathematics and physics, referring to something that has direction and is linked to movement, such as velocity (another V) or momentum in classical physics. While part of a more general play of signifiers, this technique is, I argue, also a sinthome of Pynchon's exploration of the nature of reality, arising from the philosophical underpinnings of the mathematical and scientific theories he uses.

The concept of vector acquires a new meaning in $\mathrm{QM}$, which reflects the epistemological nature of the theory, reflected in two other mathematical concepts, "eigenvector" and "eigenvalue." As signifier, "eigenvalue" enters V. as the last name of the soul-dentist Dudley Eigenvalue. "Eigenvalue," along with its counterpart, 
"eigenvector," designates an important mathematical concept, originally introduced in mathematics in German (Eigenvector and Eigenwert). These terms were initially translated as "proper value" and "proper vector," indicating their relations to a property, something that belongs to something or is owned by something, a meaning used by Pynchon. These concepts play important roles in several areas of mathematics and classical physics, but they also acquire new meaning in QM, by virtue of their relation to probability there. They entered QM with Schrödinger's version, although, as was quickly realized, both versions were mathematically equivalent. Essentially, a pair of an eigenvector and an eigenvalue allows one to predict, probabilistically, the future outcome of a quantum experiment, say, the probability that a trace of the collision between a quantum object, such as an electron, and a photographic plate, will be found in a given area of the plate. This is all QM allows us to do, in accord with what is experimentally observed, but in the RWR view, without telling us anything about the properties of this quantum object or the reality it idealizes.

$V$. offers a metaphorical rendition of this type of situation: "they discussed the concept of property and agreed that a true owner need not have a physical possession. If the soul-dentist knew (as Stencil was nearly sure he did), then 'owner,' Eigenvalue-defined, was Eigenvalue; Stencil-defined, V." (Pynchon, 1961 456-457). I register first a subtle pun on actually possessing something, say, a piece of real estate, and having something as a real state of a physical system, classical or quantum. One's proper name is itself such a possession, which makes using Eigenvalue (proper value) as a proper name especially fitting. As the signifier "stencil" suggests, what is stencil-defined is a form of image that allows one, by way of pictorial (stencil-like) realism found in classical physics, to trace a trajectory defined by the determined position and the vector (V) of momentum at any given point, and thus always predict, exactly, where the object will be found at any future time. This is not what happens if one deals with anything defined by eigenvectors and eigenvalues of $\mathrm{QM}$, eigenvalue-defined. An eigenvalue of an eigenvector only gives us the probability, $p$, to find and $(1-p)$ not to find something, in a given area, in the case of the novel, of Malta. The corresponding eigenvalue alone, as a complex number, does not give one this probability, which is always a real number between zero and one. There is, however, an additional rule, known as Born's rule, that allows one to do so. The vectors, such as eigenvectors, of $\mathrm{QM}$ are not the vectors of classical physics, associated with classical bodies and motion. They are abstract entities, defined in mathematical spaces of infinite dimensions (Hilbert spaces), and are part of the mathematical technology of calculating the probabilities of the outcomes of measurements.

One can detect in Pynchon's description a quantum-mechanical notation of two Vs, positioned horizontally, as the so-called bra- and ket-vectors, one of Dirac's inventions, which jointly form a bracket, usually associated with the wave or psi-function. A bravector, $\langle\psi|$, and a ket-vector, $|\psi\rangle$, can combine to form a bracket $\langle\psi \mid \psi\rangle$, which is a key operation in the mathematics of quantum theory. Psi-function, which reappears, as a signifier, in Gravity's Rainbow (GR), in part in juxtaposing QM and GR (general relativity), gives a spread of probabilities of finding the effect of quantum objects on measuring instruments. To quantum objects no physical properties, such as position or momentum, can be assigned between measurements. In 1935, in his famous catparadox paper, Schrödinger aptly spoke of a wave function as an "expectation-catalog" 
for future experiments. By this point, however, he was disillusioned with the theory and referred to it as "the doctrine born of distress" (Schrödinger, 1935 154, 152). ${ }^{6}$

From the RWR perspective, then, the difference between the stencil-defined and the eigenvalue-defined is as follows. What is stencil-defined is represented. What is eigenvalue-defined could only be probabilistically predicted. What is measured, say, the location of V., is, as actual, always stencil-defined. Such a "measurement" never happens in the novel, as $\mathrm{V}$. is forever left as a future possibility, just like the estate property of Pierce InVerarity in the end of The Crying of Lot 49. In such cases, we do not have anything like QM in physics for our predictions. Each such event is more like an auction, which depends, on Bayesian lines, on our experience and a singular assessment of the situation. ${ }^{7}$ But even if such a "measurement" had happened, it would, in the RWR view, not get us to the real V., but only to one or another of its stencildefined effects. This situation has psychoanalytic implications too, discussed in the next section.

Finally, "V." may, by way of a dédoublement, be read as standing for the novel itself as a literary composition that relates to effects of reality, but does not represent it, thus allowing one to read this reality, as beyond representation or even thought. The same relation is at work between what may be called the RWR of the novel itself and our reading of it, which is an eigenvalue-defined bet we take, rather than a stencil-defined certainty concerning its presumed meaning.

Vineland (Pynchon, 1985) was published two decades after $V$. and after a decade of hiatus following Gravity's Rainbow (1973), which, along with The Crying of Lot 49 (1966), I shall discuss in the next section. The use of scientific and specifically quantumtheoretical signifiers as proper names is prominent immediately, in the first sentence. The name of one of the protagonists of Vineland (Pynchon, 1985), Zoyd Wheeler, echoes John A. Wheeler, one of the visionary figures of relativity and quantum theory, and the dissertation director of Feynman and Everett. $\mathrm{Z}$ in Zoyd is likely related to Z-particle, a weak boson, predicted by QFT, along with its companion weak bosons, $\mathrm{W}^{+}$and $\mathrm{W}^{-}$, discovered just then, as well as "schiZoid," indicating the impossibility of keeping a particle identity, because in high-energy quantum regimes, governed by QFT, particles can transform into other particles, preventing them from keeping their identity. An electron can transform into a positron (an antielectron) or a photon, or an electronpositron pair, and so forth. Brought about by Dirac's discovery of antimatter in 1931, it was an entirely new feature of nature. The discoveries of $\mathrm{W}^{+}, \mathrm{W}^{-}$, and $\mathrm{Z}$ particles and the prediction of the Higgs boson (confirmed in 2005), are, for now, a culmination of this doubly Heraclitean nature, combining becoming against Being and the many against the One, a feature playfully captured by this signifier, as well as that of "Wawazumi Life \& Non-Life corporation," "W+aW-aZumi," discussed below.

Importantly, these transformations are discontinuous: particles are born and disappear, and new particles appear instead. The mathematical entities themselves predicting these changes are called creation and annihilation operators. The process is radically different from, say, Ovid's metamorphoses, defined by one or another continuity, like Daphne transforming into a laurel, or Narcissus into a flower still looking at the same pond. In this respect, the word "transformation" should be used with caution, only as relating to different effects of RWR, which cannot be seen either in terms of being or in terms of becoming, any more than in any other terms. 
Is this play of signifiers a sinthome of a relation to RWR in the human world? Yes, it is. Thus, Pynchon aims beyond only inscribing the (continuous) becoming of the characters, as, for example, in Virginia Woolf's Waves (Woolf 2019) which has quantum resonances, but, I would argue, ultimately settles for a classical-like fusion of becoming and the multiple as a continuous process. (Schrödinger originally envisioned the ultimate nature of quantum reality as waves, which might have influenced Woolf's novel, published in 1931.) There is this type of character portrayal in Vineland as well. A more radical, however, and, I think, less appreciated feature is that a character such as Frenesi Gates, a sort of QFT-like version of V., is transformed into a completely different type of person, or again, on the QFT model, suddenly disappears as one type of person to reappear as an entirely different one from the RWR of life. Characters, major and minor, emerge from nowhere, that is, from the RWR of life, sometimes as the same as before, sometimes as something very different, different entities or parts, in the sense of a part in a play. A reader, just as the novel's other characters, may surmise but may never know the reasons or causes of these transformations, and there may not always be assigned causes. Indeed, not only characters, but the world itself in which they exist, Vineland, appears as a manifold of such transforming effects of the real, as RWR, effects sometimes random, sometimes partially ordered, including by (cor)relating some of them.

27 To adopt, metaphorically, another QFT-concept, that of virtual particles, in the RWR of QFT, the existence becomes something virtual before emerging as something that manifests itself in the actual. According to Deleuze and Guattari, who borrow the idea from QFT: "Chaos is defined not so much by its disorder as by the infinite speed with which every form taking shape in it vanishes. It is a void that is not a nothingness but a virtual, containing all possible particles and drawing out all possible forms, which spring up only to disappear immediately, without consistency or reference, without consequence" (Deleuze and Guattari 1994, 118). "Quantum foam" and "the Quantum Dragon" were two names given to this type of process in physics by Wheeler-John Archibald, not Zoid. What is Philosophy? would not have been familiar to Pynchon at the time. However, this type of view of the real as virtual vs. the actual, which at certain points emerges from the virtual, is found in Deleuze and Guattari's earlier works, for example in the presentation of their theory of schizophrenic desire, as irreducibly multiple vs. the oneness of the Oedipal, in Anti-Oedipus. The book is, mockingly, mentioned in the novel: "Fortunately Ralph Wayvone's [WayVone] library happened to include a copy of the indispensable Italian Wedding Fake Book, by Deleuze and Guattari" (Pynchon, 1985 97).

As in QFT, in Vineland, the virtual, that is, whatever effects it had in the past, is only something that characters could surmise with one probability or another, but about which they could never be certain. Our records, archives, only give us very limited information. Frenesi Gate's life, as appears to her daughter, Prairie, is a key example. It is, again, true, and is one of my points here, that one does not need QFT theory to see this type of transformation in Vineland. Pynchon's bringing QFT into play via his namesignifiers functions is a sinthome of the view of the real, possibly as RWR, and its discontinuous transformational effects. Even the ultimate human discontinuity, that of life and death, becomes part of this play, because some of the dead characters reappear, as the novel defines them, as Thanatoids, who are "like death, only different" (Pynchon, 1985 170). 

nonlife is a key feature of the novel. Allegorically, it represents the fact that in our mental world, the distinction between the living and the dead is complex, as enacted, in a tragic mode, in Joyce's “The Dead," likely on Pynchon's mind (Joyce, 1993 75-97). Vineland explores this in a more comic mode, albeit not without reference to human and societal tragedies between the 1960s and 1980s. There is also the following difference. "The Dead" or most of Joyce's fiction, especially his early fiction, but even Ulysses, still maintains the continuous, if transforming, identity of its characters. By contrast, as just discussed, in Vineland, one finds the discontinuous transformation of characters, even living ones, into something different. The same, again, is true, now in affinity with Finnegans Wakes, about the transformations, often radically discontinuous of the world, itself both alive and dead, or Thanatoidal, like death, only different. corporation, has a double link to quantum theory, both QM and QFT. Its first, Wawazumi, part, again, relates to the triplet of weak bosons, $\mathrm{W}^{+}, \mathrm{W}^{-}, \mathrm{Z}$, at the time the ultimate manifestation of the nature of QFT theory. The second, Life \& Non-Life, appears to relate to a famous thought experiment, known as the Schrödinger cat paradox. I shall now suggest how these two phenomena, that is, the corresponding translations of each into two features of the novel, can be brought together, explaining the fusion of these two signifiers. poison may or may not be injected by means of a quantum event, such as a radioactive decay, with a given so-called half-life of, say, two hours-which, being quantum, has a fifty-fifty probability of occurrence during these two hours; after which we open the box. QM correctly predicts this probability, and once we open the box the cat will be found either alive or dead. This is sometimes seen as a paradox because it is difficult to assume that the cat is not either dead or alive even before one opens the box. There are several possible ways of handling it. I shall only mention the three most relevant here. First, one can see the cat in the so-called superposition of two states, alive and dead, captured by the wave-function before the box opened, which wave-function then "collapses" (a technical term) into one of the two states, once the box is opened. Second, the many worlds interpretation resolves the paradox by maintaining that there are two cats in two different worlds, in one of which it is alive and in the other dead. Third, in the RWR view, there is no superposition of the states of the cat, but only a superposition of two elements of the formalism of QM, known as "state vectors," $\mid \psi>$, mentioned above, which allows us to predict the fifty percent probability of the quantum radioactive decay while the cat is in the box and hence for either outcome once we open the box. QM, in this view, tells us nothing about the cat inside the box, which (unlike the radioactive decay) is considered a classical macro object, whose behavior is not described by QM. Indeed, in the RWR view, QM does not describe the decay either but only predicts the probability of its occurrence. So, there is no paradox. I am not sure that Pynchon follows the many worlds view in Vineland in the way he might be doing in Mason \& Dixon, as discussed below. Pynchon appears to, metaphorically, adopt a view, in principle consistent either with assuming the superposition of the states of the cat itself or the RWR view, in which case one only deals with the probability of either outcome when the box is opened. So, either reading is possible, with the first one possibly also reading Thanatoids as representing this type 
of superposition. A given character, say, again, Frenesi Gates, can appear, as in fact she does several times, or be discovered. It is difficult to predict whether she will be revealed as dead or alive, or as a Thanatoid, and, if alive, as it actually happens, whether or not she appears as an entirely different character, with the original Frenesi Gates no longer existing.

These more multiple possibilities join the cat-paradox metaphor with that of $\mathrm{W}^{+} \mathrm{W}^{-} \mathrm{Z}$ of QFT. One can sketch it as follows, by way of a physically unrealizable but Pynchonesque metaphor. The Schrödinger cat experiment could be performed, although one would not want to do this, and there is no need, because no one doubts that doing so will confirm it. On the other hand, if one considers a fictional "QFT" version I shall now describe, it can only be performed with quantum objects, such as electrons or photons, and not with classical objects like a cat. In this fictional version, once one opens the box, one could find there not only the cat, dead or alive, but also some other creature, say, a mouse. Nor can one be sure that it is the same cat, even if it looks exactly the same.

This cannot happen in life, but literature can play with such a world, as in Vineland or its precursors in magic realism or science fiction, thus, at least in some readings, making this situation an allegory of our interaction with the real as RWR. One deals with chance events and the probabilistic estimates of their occurrence that are not underlined by causality. Events happen but we do not know or even cannot imagine why. We cannot think, know, or speak about the ultimate nature of the real, as RWR, but we can think, know, and speak of its effects, as the actual, which is a form of reality, but not the ultimate nature of reality. As with high-energy quantum phenomena, governed by QFT, in Vineland one never knows who or what is going to appear from the past and as what. It could be somebody presumed dead appearing as alive, which is not so uncommon in literature or life. Or it could be somebody who has become something very different altogether, which is less common, but happens, too. Or it could be a Thanatoid, "like death, only different," which cannot happen in life, but is an allegory of what happens in life. It may, for example, represent certain persons that are found in our mental life, and not only in dreams, in our interaction with the world, with "all the living and the dead," as Joyce said in ending "The Dead." Michael Furey, the Dead, is akin to a Thanatoid in the mind of and, in a way, life of Gretta Conroy in "The Dead" (Joyce 1993, 97). Pynchon offers a comic rendition in the "life \& no-life" of Vineland:

Radio Thanatoid arrived with a remote crew to beam and bounce the proceedings out to the other pocket of Thanatoia here and there in the country of the living, "Direct, though not necessarily live," as the announcer put it. A tour bus, perhaps only lost in the night, swept in with a wake of diesel exhaust and waited idling for its passengers, some of whom would discover that they were already Thanatoids without knowing it, and decide not to reboard after all ... And the band, Holocaust Pixels, found a groove, or attractor, that would've been good for the entire transnight crossing and beyond, even if Billy Barf and the Vomitones hadn't shown up later to sit in, bringing with them Alexei, who turned out to be a Russian Johnny B. Good, able even unamplified to outwail both bands at once. (Pynchon, 1985 384).

"Attractor" is a term likely adopted from chaos theory, fashionable then, to which the unfolding of events here described could be connected as well, but I shall put this aside, to remain with a more quantum-like version of the event manifold closing the novel. The last pages of the novel are populated with a large number of characters and connections, reminiscent of photographs, such as those of the traces from interactions and collisions from particle accelerators, by using which at the time, $\mathrm{W}$ and $\mathrm{Z}$ particles, 
and more recently the Higgs boson, were discovered. Very different from the QM picture on which Pynchon bases V., these photographs show huge networks, a frenzy, of traces from which the existence of particles and their identities could be inferred. These images are gates, "frenzy gates," into the quantum Real. Frenesi Gates is, again, a V. of Vineland, amidst this irreducibly multiple world of characters and events, in a much richer space of variations, which are, at least on one reading, effects of RWR, the real beyond thought. Gravity's Rainbow mediates this change towards the multiple. Causalities of these effects are often uncertain or even cannot be assumed: there are only probabilities.

Still, these aspects of the novel only represent the structure of our interaction with the real, including as RWR in life and in Pynchon's works. This structure alone cannot account for the richness and complexity of characters, interactions, and events of life, or literature. No mathematical or scientific model is sufficient to do so. Consider the conclusion of Vineland:

The small meadow shimmered in the starlight, and her promises grew more extravagant as she drifted into the lucid thin layer of waking dreaming, her flirting more obvious-then she's awake, alert to some step in the woods, some brief bloom of light in the sky, back and forth for a while between Brock fantasies and the silent darkened silver images all around her, before settling down into sleep, sleeping then unvisited till around dawn, with fog still in the hollows, deer and cows grazing together in the meadow, sun blinding in the cobwebs on the wet grass, a redtail hawk in an updraft soaring above the ridgeline, Sunday morning about to unfold, when Prairie woke to a warm and persistent tongue all over her face. It was Desmond, none other, the spit and the image of his grandmother Chloe, roughened by the miles, face full of blue-jay feather, smiling out of his eye, wagging his tail, thinking he must be home. (Pynchon, 1985 384-85)

Vineland, Pynchon's other novels, or literature in general are, ultimately, about capturing such complex landscapes of our mental life in its essential immanence, as Deleuze would have it, the immanence of waking and dreaming, waking dreaming and dreaming waking, in their incessant interactions with equally complex landscapes of the world and with "all the living and the dead," invoked, once again, by Joyce in closing "The Dead" (Joyce, 1993 97). Even this more realist depiction proves this, and Pynchon's novels, have many more tangled ones. This is why one needs literature, helped by philosophy, psychology, anthropology, and other human sciences. No scientific theory can do so, but some of them can suggest, as QM does, that we might need to rethink the structure of our interactions with the world.

In his 1916 "The Unconscious," Sigmund Freud compared the unconscious to the way nature appears in quantum theory, then on its way to QM (Freud, 1963 121). This parallel, however, or those with other aspects of quantum theory, again, have to do with the structure of the effects of the real. They tell us little about the workings of the unconscious in its psychoanalytic richness and the specificity of its effects. Quantum theory cannot be reduced to this structure either, given the richness of its experimental data and the mathematics it uses, itself a form of composition, to do so, even though this richness is, again, hardly comparable to that of life. This difference is even more pronounced in the case of Pynchon's use of theories dealing with chance and probability, classical and quantum. These theories help him to suggest different ways in which one can relate to reality, including as RWR, through its effects in the world. But the richness of these effects is defined by his literary inventiveness that is far beyond these relations. Readers attentive to Pynchon's use of mathematics and 
science will quickly realize this, while other readers will relate to this richness, or the structure of our relations to the real, bypassing these connections.

\section{The Quantum Anti-Oedipus}

The Crying of Lot 49 (1966) and Gravity's Rainbow (1973) would confirm this asymmetrical balance of the scientific and the literary. In The Crying of Lot 49, only one of the three demons of chance, Maxwell's demon, figures expressly, connecting entropy and information. This connection, which, however, requires the angel of probability to work, is one of the great discoveries of modern physics, which eventually entered quantum theory, leading to quantum information theory. That, however, happened only by the time of Against the Day, and quantum information theory does not appear to figure in Pynchon's works. ${ }^{8}$ This aspect of The Crying of Lot 49 has often been read on lines of classical statistical physics or thermodynamics. Just like $V$., however, the novel may also be read as an exploration of various possible relationships between chance and probability, governing the singular trajectories of the characters' lives and their interactions: those ultimately governed by causality, on the model of classical statistical physics, or those governed by RWR, on the model of QM. I shall now sketch the second type of reading.

The protagonist, Oedipa Mass, whose first name is linked to, via its male counterpart, Oedipus, to a causal law of fate (after Sophocles's Oedipus the King), might be set to discover that she must deal with the effects of a RWR, but, if so, only just before or more likely after the novel ends. In the course of the novel, Oedipa, appointed executrix of the estate properties of Pierce Inverarity, assumed that figuring out the arrangement of these properties should be governed by some sort of causal laws. This stencil-defined assumption that a belief in the angel of causality is natural and within certain limits is unavoidable. But it may be insufficient, and this insufficiency makes this quest continually go astray, because any assumed causal connection is subverted soon after it is assumed. Nor, conversely, can one assume, by way of an absolute reversal, that the situation is random, which might appear as the only alternative to causality, but is not, in view of the quantum-mechanical-like probability. As indicated earlier, the random, pure-chance, alternative would, demonically, paralyze any strategy of action in life, which always relies on probability. This absolute reversal is found in Oedipus the King, and it may be called "the Jocasta ontology" because it was expressed by Jocasta, Oedipus's mother and wife: "Fear? What should a man fear? It's all chance, chance rules our lives. Not a man on earth can see a day ahead, groping through the dark. Better to live at random, best we can" (Sophocles 146). This view is proven illusory in the play: the lives of the characters are ultimately ruled by fate, conceived in terms of causality. The accumulating evidence helped Oedipus to discover the tragic trajectory of life and who he ultimately is, by updating, on Bayesian lines, his estimate of the probability of his crimes, from zero initially to certainty in the end.

This approach, however, does not appear to help Oedipa: new information gained in her investigation does not bring her asymptotically closer to a discovery of the nature of any properties at stake, from Pierce's estate to her own knowledge of who she is, psychoanalytically speaking. Instead, while not strictly chaotic, it appears to obey a different, QM-like, law of organization. A more quantum-mechanical-like, eigenvaluedefined, understanding of Pierce's properties and way of life in general appears to be 
necessary. While it defeats a strictly causal reasoning, a QM-like approach to life allows for a form of order and hence probabilistic thinking, an order that is, however, underlaid, in the RWR view, by something real beyond thought, and thus cannot be figured out or figured, no matter how much evidence one gathers. The novel ends on an auction, a paradigmatic event of the interplay of numerous trajectories, or nontrajectories (discrete sets of events), of the lives of sellers and buyers, those who set up the auction, and auctioneers.

The question is what, again, the law of this interplay of chance and probability is. The novel's answer may not only be that we cannot always count on causality and must sometimes reason in a quantum-mechanical way, but also that there is no single such law of either kind. Life's law of contingency is the multiplicity of such laws, which also includes the unlawful, which makes certain events purely random. This complexity is helped by the detective dimensions of The Crying of Lot 49, recasting those of Oedipus the King. ${ }^{9}$ But this is only one part of the great game of contingency; the interplay of chance and causality (or necessity, a proximate category), and contingency defines the very concept of play, allegorized by Pynchon's novels as well.

41 How, then, do we make our decisions, when the angel of causality, who helps us sometimes, abandons us, or when we must abandon it? When we deal with quantum phenomena, we have QM or, in high-energy regimes, QFT. But life is too complex for any single theory to handle our decision, which is true even in the case of causal relations, found in our life as well. There are statistical similarities and patterns, which allow a wide use of statistical theories as sociology, economics, or psychology, although not really in psychoanalysis, where while there are general principles and even theories, Freudian, Lacanian, or other, each case is still too singular. Literature, too, tends to deal with singularities. When such singular events are random, along the lines of Jocastan ontology, there is nothing one can do in making one's decision how to proceed after each event. But they are not always random and may allow us to make estimates on the basis of the knowledge we have. One can, however, no longer adopt a statistical view, which assumed multiplicities of events that could be averaged. Only a Bayesian approach, which deals with unique events, is possible, although using patterns of similar cases may help our estimates. But the reasons for and patterns of predictions may change with each new event, whether predicted earlier or unexpectedly random. The hidden real of the Tristero, which haunts Oedipa's quest by its messages, may, then, be read as a sign of RWR responsible for such discrete events, which requires us to change our way of thinking concerning what happens next, rather than as a sign of a hidden causal system, which governs the field and which, once figured out, allows us to handle the overall situation. For an effective scientific practice to be possible, one needs regularities, causal or statistical, beyond those found in each singular situation. But literature, again, tends to explore singularities and opens the space for the quantum-like, RWR perspective, and with it, probability without causality into our decision making. This is, again, akin to an auction, which is perhaps why The Crying of Lot 49 ends there, in unending a sequence of unique events, for which no connecting trajectory may be assumed.

Thus, we might ultimately be dealing not with Maxwell's demon, where uncertainty is helped by the angel of causality, but with Heisenberg's demon of uncertainty, or even with the demon of uncertainty beyond $\mathrm{QM}$. In considering quantum phenomena we, again, can always rely on the same theory, QM, just changing the data we use. The real 
beyond thought, RWR, announced by the sign of the Tristero, not only changes the information each time but, each time, requires new ways of estimating the future or figuring out the past, which figuring, however, only happens in the future, Nachträglich, après-coup, just as it does in psychoanalysis.

Gravity's Rainbow offers an even more complex exploration of this basic structure: Something happens. How is it possible? What is the cause? Can one assume a cause? The setup of Gravity's Rainbow is the improbable coincidence of two statistical distributions-that of London locations where German V2 rockets hit and that of the protagonist Tyrone Slothrop's sexual encounters. The idea appears to be borrowed, loosely, from famous quantum experiments, the Einstein-Podolsky-Rosen- (EPR) type experiments, that concern correlations between quantum events (e.g., Mermin 110-176). These experiments deal with two sequences of specifically prepared paired quantum events. While the outcome of each paired event is random, as the measurements continue, the outcomes satisfy strict probabilistic laws. How is this possible? If each outcome is strictly random, how can we get a strict probabilistic order for many repeated outcomes? Indeed, as noted from the outset, quantum phenomena are most remarkable for the mysterious fact that, in certain circumstances, such as those of the EPR-type experiments, random individual events combine to form a statistically correlated order. The mystery would disappear if one assumed that this order is causal, with the randomness only apparent (which is sometimes known as a common cause, the concept introduced by Hans Reichenbach) or that there is an action at a distance between such events, which connects them. Einstein famously called it "a spooky action at a distance." The novel suggests both as possibilities (without settling on either), even though each poses difficulties in physics. The RWR view avoids both by placing the ultimate nature of reality responsible for correlations beyond conception (e.g., Plotnitsky 2020a). We do not know or cannot even conceive how correlations are possible or why QM predicts them. Thus, the RWR view allows for a certain sense of mystery in quantum theory, but in the absence of any mysticism, "foreign to the spirit of science" (Bohr, 1987, v. 2, 65). Quantum correlations are mysterious because we cannot conceive of how they come about. But they do not require one to assume some mystical agency in charge of this situation, as in mystical or negative theology, which presupposed such an agency, while denying that any conceivable properties could be attributed to it.

The Slothrop correlations, as they may be called, are only loosely modelled on the EPR correlations. But they pose a similar question: how are they possible, again, given the apparent randomness of each sequence, considered independently? ${ }^{10}$ The group that studies and experiments on Slothrop is called (no surprise here) a psi-section, where, even more than for psychology, psi stands for the psi-function of Schrödinger's equation, which, as discussed above, is the primary probabilistic mathematical vehicle of QM.

At a certain point, the novel suggests an explanation of the Slothrop correlations in terms of a common cause, defined by the fact that Slothrop was conditioned as an infant, "baby Tyrone," by the creator of Imipolex G (a chemical used in the guidance system of the V2 rocket), Laszlo Jamf. At one level this is not surprising: fantastical as the case may be, one deals with macro-level phenomena (the explanation is based in chemistry and not in physics), where a common cause would be more likely. Secondly, and more significantly, tracing this cause, a tracing that also becomes Slothrop's own, 
helps Pynchon to add to an enormous richness, narrative, conceptual, metaphorical, psychological and so forth, of the novel. However, this common cause solution is never made definitive and even the story of Imipolex $G$ is questioned, as are those of Slothrop's sexual exploits and of the Slothrop correlations. Versions of an-action-at-adistance explanation, like precognition and psychokinesis, are mentioned, too, but never seriously entertained (e.g., Pynchon, 1973 98). Quantum-mechanical-like indeterminism, defined by a form of RWR appears just as likely, similarly to $V$. and The Crying of Lot $49 .{ }^{11}$

As its predecessors, Gravity's Rainbow is suspended between demons of chance and angels of probability, two types of angels of probability, angels governed by causality behind probability and angels of probability without causality, angels of quantum-like correlations, as effects of RWR. These demons and angels hover over the manifold of theories-scientific (mathematical, physical, chemical, and biological), psychological (Freudian vs. Pavlovian), or sociological. The novel even embodies (perhaps deliberately) the conflict now defining fundamental physics, that between Einstein's relativistic theory of gravity (a causal theory) and QM. Each theory is true within its proper limits, but they are incompatible. This conflict is already implied by the signifying conjunction of the novel's title, combining gravity and rainbow. A rainbow is an optical and thus ultimately quantum phenomenon.

As indicated, the structures of our relationships with reality and the role of chance and probability in these relationships, realist and causal or RWR (in which case they are probabilistic in the absence of causality), have psychoanalytic implications in all Pynchon's novels, but arguably especially in The Crying of Lot 49 and Gravity's Rainbow. I shall now sketch an RWR reading of these implications. While the RWR-type view would not deny the psychoanalytic (say, Freudian or Lacanian, or anti-Oedipal ones of Deleuze and Guattari) structures of the unconscious, these structures appear as effects that are results of "measurements" performed by thought on the deeper RWR-type unconscious reality, which is beyond thought and hence cannot be assigned structures. Freud aims to assign structure, in particular, an Oedipal structure, to the real and to give causality and even determinism to its effects. Lacan, too, ultimately appears to subordinate the workings of the unconscious and the multiplicity of its effects to the causal control in the Symbolic. In other words, the question is, again, whether the play of effects, manifested in the networks of signifiers, can be controlled, for example, by a master signified or signifier, in particular the Oedipal one, Freudian (a master signified) or Lacanian (a master signifier), or cannot be so controlled, making this play dissemination in Derrida's sense, underlaid by the RWR view (Derrida 2017).

Indeed, both Freud's and Lacan's actual arguments tell us, against their own grain, that such a control may not be possible, given the ultimate nature of the Real (e.g., Deleuze and Guattari 2009, 38-41, 56-67). Thus, is Pierce Inverarity a father figure? Or is a father, rather, something like Pierce Inverarity, from the signifiers of his name to his role as a property owner, which are among many possible figures of what is, Oedipally, the father figure? Each of these possibilities may emerge in the interplay of chance and necessity, or chance and correlational patterns, in the play of effects of a reality that is, as RWR, beyond the reach of any such figure. The same play can be found in Gravity's Rainbow. Multiple signifying chains may, as Deleuze and Guattari argue, lead to the rise of Oedipal desiring machines, which Lacan's Symbolic represents as well, and often do in our Oedipalized world, but they need not. Neither the Oedipal nor the anti-Oedipal is 
inherent in RWR, and they arise only in our interactions with it. The question becomes how far we, or psychoanalysis itself, are Oedipalized, thus surrendering the irreducible multiple and its chains, as chains of probabilities without causality, to the causal control imposed from the outside, Freudian or, especially, Pavlovian. (Jungian psychoanalysis figures in Gravity's Rainbow as well.) How much do we want or have to surrender, from within and from without, the eigenvalue-defined, psi-function, of our multiple unconscious to the stencil-defined control of the Psi-section? The Psi-section cannot tolerate the psi-function, which threatens, in Pointsman's words, "the end we all struggle towards in science [...] the true mechanical explanation. [...] No effect without a cause, and a clear train of linkages" (Pynchon, 1973 102). The psi-function of $\mathrm{QM}$ is about effects without causes and the trains of probabilities without linkages. The section is Pavlovian in the novel, but it can stand for any control system, governed by totalizing desiring machines, against the schizophrenic anti-Oedipal one of Deleuze and Guattari, with Anti-Oedipus published, in 1972, just before Gravity's Rainbow.

This control is something that Slothrop tries to defy or at least resist, but, like Oedipa, cannot resist enough, except perhaps in his final Thanatoid "scattering": "Some believe that fragments of Slothrop have grown into consistent personae of their own. If so, there's no telling which of the Zone's present-day population are offshoots of his original scattering" (Pynchon, 1973 866). Psychoanalytically, with Pavlov out of the way, the novel ends with Freud after all, who is invoked a bit earlier by the character, named Thanatz, in the context of sado-masochism, immediately shifted to a more antiOedipal, Sado-anarchism (Pynchon, 1973 860). Pynchon's final image of Slothrop is a tour de force: "There's supposed to be a last photograph of him on the only record ever put out by The Fool, an English rock group-seven musicians posed, in the arrogant style of the early Stones, near the old rocker-bomb site, out in the East End, or South of the River" (866). There is a nice auto-biographical touch, reflecting Pynchon's notorious refusal to be photographed. But the key is Slothrop's return to a rocket-bomb site, one of those to which his war-time sexual exploits are connected in the novel setup. Pynchon's "uncertainty principle" kicks in next, however: "There is no way to tell which of the faces is Slothrop's: the only printed credit that might apply is 'Harmonica, kazoo-a friend.' But knowing his Tarot, we would expect to look among the Humility, among the gray and preterite souls, to look for him adrift in the hostile light of the sky, the darkness of the sea..." (Pynchon, 1973 866). It may not be Slothrop's photograph, after all.

This or other uncertainties permeating the novel do not, however, affect its certain, nearly mathematically rigorous structure, as it still brings Slothrop's QM- or QFT-like scattering to the site of the Slothrop, QM-like correlations. These uncertainties only affect, indeed define, what this structure offers to the reader: irreducibly complex networks of realities, causalities, chances, and probabilities, "an affirmation that is irreducible to any sort of unity" (Deleuze and Guattari, 2009 42). That much is hardly in question. Are these multiplicities effects of reality without realism? At least, they may be read as such.

\section{Modernism Against the Day}

51 Both Mason \& Dixon (1997) and Against the Day (2006) offer the reader the same type of landscapes. These landscapes are, in these novels, also actual landscapes, territories, as 
well as spaces of escape (not exile!) from territories-deterritorializations, as Deleuze and Guattari would call them. These spaces are alreaedy found in Gravity's Rainbow ("the Zone") and Vineland ("Thanatoia"), but are more pronounced in Mason \& Dixon and Against the Day. Mathematics and science, including those dealing with chance and probability, continue to figure prominently in both works. On the other hand, while one finds manifested quantum-theoretical elements in Mason \& Dixon, there are at most only a few possible indirect intimations of quantum theory in Against the Day. According to the physicist Sean Carroll, juxtaposing Mason \& Dixon to "Entropy":

Just as a paradigmatic example of a particularly blunt use of physics in literature is provided by the young Pynchon in his story "Entropy," a compelling example of an extraordinarily subtle use of such inspiration is provided by the mature Pynchon in his novel Mason \& Dixon. [...] At one point early in the book, the surveyors puzzle over a letter they have received from the Royal Society:

"You suppose this is Bradley's voice? I think not, for I know him,"-Bradley cannot write like this, even simple social notes give him trouble. '...Whenever their circumstances, now uncertain and eventual, shall happen to be reduced to Certainty.' Not likely."

"Eeh, thah's deep...? 'Reduc'd."'

"As if... there were no single Destiny," puzzles Mason, "but rather a choice among a great many possible ones, their number steadily diminishing each time a Choice be made, till at last 'reduc'd,' to the events that do happen to us, as we pass among 'em, thro' Time unredeemable,-much as a Lens, indeed, may receive all the Light from some vast celestial Field of View, and reduce it to a single Point. Suggests an optical person,-your Mr. Bird, perhaps." (Pynchon, 1997 45)

Here Pynchon has given just enough of a hint to suggest a metaphor that will recur throughout the book-that of the collapse of the wavefunction in quantum mechanics. Mason's description of multiple destinies, steadily diminishing in reality until reduced to a single observed situation, fits perfectly with the conventional Copenhagen interpretation of wavefunction collapse (sometimes referred to as "reduction" of the state vector). One of the most profoundly counter-intuitive features of quantum mechanics is that systems can be in superpositions of ordinary states-a cat that is half alive and half dead, in Schrödinger's famous thought experiment. It is the act of observation that converts these multiple co-existing realities into a single observed truth. Pynchon portrays the westward progress of Mason and Dixon as a series of such observations-before they cross a certain hill, it is not only conceivable that various fantastic possibilities might describe the other side, but all of these possibilities really do obtain, until the surveyors' actions collapse them into a single reality. Of course, such a manifestly twentieth-century notion would appear to be completely anachronistic in a novel set in the eighteenth century; but Pynchon regularly makes cheerful use of such anachronisms, and there is no reason to believe that he would hesitate to refer to profound ideas of modern physics in a novel about progress at the dawn of the Age of Reason. Science has provided the author with a particularly rich metaphorical idea, and the absence of any explicit discussions of quantum mechanics in the book is no reason not to take advantage of it. (Carroll, 2005 12-13)

While I agree with Carroll on his last point, I do not, as explained earlier, share his interpretation (and it is only that!) of the cat paradox or his preference for the manyworld interpretation, in which possible worlds are assumed to be real, which he advocated more recently (Carroll 2019). It is true that while the wave-function gives us probabilities, an experiment, once performed, gives us certainty. This fact, however, 
need not imply "multiple co-existing realities" which "the act of observation converts [...] into a single observed truth." It equally allows for the RWR-type view of QM, beginning with that of Bohr, in which there are no multiple co-existing realities but only multiple coexisting possibilities, and hence no superposition of the outcomesthere is no moment in which the cat is half dead and half alive!-but only a superposition of possible outcomes. This would suggest the corresponding reading of the quantum-mechanical-like aspects of the novel. But Carroll's reading is possible, too, in view of other intimations of many-world interpretations of QM in Mason \& Dixon. In particular, the multiple narratives of The Revered Wicks Cherrycock (an anachronistic signifier that hardly needs a quantum-like interpretation) may be read as a sort of many-world interpretation of the events. But then, again, they may also be read, on lines of Feynman's path-integral formulation of QM, as possible ways in which things might happen, with different probabilities. Either interpretation, again, only refers to the structure by means of which the novel's narrative multiplicity is organized and does not capture the multifarious richness and intricacy of each of these narratives or their interactions.

Against the Day is equally shaped by the interplay of chance and probability, beginning with the flight of the balloon, named "Inconvenience," and the teams named "The Chums of Chance," around which flight in the novel is organized. This makes this interplay arguably more classical-like, as the flight of any balloon would be. Intriguingly, amidst the profusion of mathematical and scientific references, quantum theory is never mentioned in the novel, although it was a major feature of the mathematical and scientific landscape, including in Göttingen (a key locale in the book's portrayal of mathematics), during the time of the narrative from 1883 to just after World War I. David Hilbert, who figures in the novel, lectured on quantum theory, including Bohr's 1913 atomic theory there. And yet, elements and language of the quantum, or relevant to the quantum, such as those of particles and fields, are still found in the novel, even while describing phenomena treated classically. Consider this passage: “'[...] violent ensembles of energy state, Brownian movements...' And in fact the next time she visited Tancredi, Dally thought she could see emerging from the glowing field of particles, like towers from the forschetta, a city, a contra-Venezia, the almost previsual reality behind what everyone else was agreeing to define as "Venice" (Pynchon, 2006 586). Although Brownian motion is a classical phenomenon, this is conceptually close to Schrödinger's sense of reality that led him to his wave mechanics.

The novel is famous for its depiction of the landscape of modern mathematics and science during the period it covers. So much that came to define twentieth-century mathematics and science, or technology, is found there. Several chapters take place in the mathematics department of the University of Göttingen, the birth-place of many key developments of modern mathematics. Its greatest German figure, Hilbert, the towering presence in Göttingen, and his French counterpart, Henri Poincaré, make their appearances. Göttingen was also the birthplace of QM, discovered by Heisenberg there, and much research on relativity was done there as well. One of Pynchon's signature songs comically captures this landscape:

Her idea of banter

Likely isn't Cantor

Nor is she apt to murmur low

Axioms of Zermelo,

She's been kissed by geniuses, 


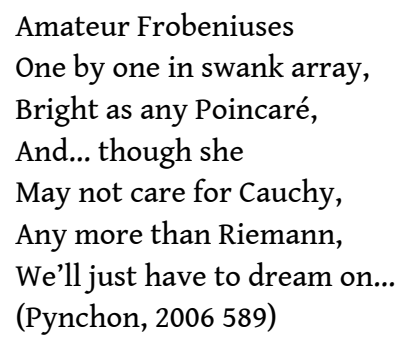

These are the names of some of the key figures of contemporary mathematics, signatures under these developments. There have been several good analyses of the role of mathematics in Against the Day by literary scholars and mathematicians (e.g., Berressem 2018, Engelhardt 2019, Harris, 2015 128-138). Throughout this article, however, I would like to ask a different question, at most only intimated by Berressem and Engelhardt. What is this persistence of mathematics in the novel a sinthome of, and how, if at all, is this sinthome connected with the sinthome defined by Pynchon's use of chance and probability?

My answer originates in the historical circumstance that the rise of this mathematics coincides with the rise of modernism in literature and art. As I shall explain presently, this mathematics, too, can be seen as modernist. As a result, Against the Day becomes an allegory of modernism, some of which also involves the RWR view, in which case I shall speak of "radical modernism." Making mathematical modernism part of the global landscape of modernism does not diminish the role of chance and probability there, although both are more essentially connected to physics. For one thing, modernist physics, such as relativity and $\mathrm{QM}$, used modernist mathematics, respectively Riemannian geometry and Hilbert spaces, in the latter case in order to establish strictly probabilistic connections to the RWR at stake. Modernism in literature may even be seen as posing this question, beginning with Stéphane Mallarmé, one of the founding figures of literary modernism. According to Badiou: "Mallarmé represents the person who launched a poetic challenge to mathematics by assuming that the rigour of poetic language could equal the rigour of mathematics, but moreover also assumed the power of Chance, something mathematics cannot do" (cited in Boncardo and Gelder 85).

To make a similar case for Pynchon, I briefly revisit modernity and modernism as historical categories, first. It is, again, a matter of interpretation whether either Mallarmé's or Pynchon's works, or which among them, represent radical modernism, in which case this combination of the mathematical-like rigor of literary composition and the role of chance and probability is accompanied by the RWR view (e.g., Plotnitsky $2000 a, b)$. Modernity is a broad cultural category. It refers to the period of Western culture extending from about the sixteenth century to our own time: we are still modern, although during the last fifty years or so, modernity entered a new stage, postmodernity, shaped by the rise of digital information technology. Postmodernity, however, also amplified modernist epistemological trends, such as the role of the unthinkable in thinking, in art, philosophy, and mathematics and science (e.g., Lyotard 1987). Modernity is defined by several interrelated transformations, sometimes known as revolutions, although each took a while. These revolutions were scientific (defined by the new cosmological thinking, beginning with the Copernican heliocentric view of the Solar system, and the introduction of physics as the mathematical-experimental science by Descartes, Galileo, and Newton), industrial-technological (defined by the transition to the primary role of machines in industrial production and beyond), philosophical-psychological (defined by the rise of the concept of the individual human 
self, beginning with Descartes's concept of the Cogito), economic (defined by the rise of capitalism), and political (defined by the rise of Western democracies).

One might add to this standard list the mathematical revolution, rarely discussed as such, although sometimes considered as part of the scientific revolution. Descartes, again, is a central figure, as a creator of analytic geometry, which also prefigures mathematical modernism in mathematical modernity. This history also puts in a different perspective the prominence of parabolic curves in Pynchon, for example, in Gravity's Rainbow, a prominence noted by commentators (e.g., Harris 128-137). The concept of a curve, specifically a quadratic, such as parabolic, curve, was radically rethought by Descartes in his analytic geometry. On the one hand, this project is contemporary and coextensive with the rise of classical physics, where the motion of bodies is commonly described by quadratic curves, such as, paradigmatically, elliptical orbits of planets moving around the Sun under Newton's law of gravity. On the other hand, it is an intimation of modernist thinking in mathematics, defined by its break from the project of representing natural objects and thus from classical physics. Analytic geometry, by in effect making geometry algebra, gave mathematics its de facto independence of any referential connection, via physics or otherwise, to the material world. It did so because the equation corresponding to a curve, say, $Y=X^{2}-1$, for the corresponding parabola, could be studied as an algebraic object independently of its geometrical representation of natural processes and thus its connection to physics. A curve becomes defined by its equation, divested of its representational geometrical counterpart. It no longer idealizes any reality exterior to it. It only represents itself, is its own ontology, akin to a poetic line (a rhythmic curve) divorced from its functioning, especially, a representational one, as in ordinary language. The equation is the poetry of the curve. Mallarmé's modernism was inspired by this view of mathematics as a nonrepresentational composition (Plotnitsky 2020b).

In contrast to modernity, "modernism" is a well-established denomination only when applied to literature and art. It refers to certain developments in the first half of the twentieth century, from roughly the 1900s on, represented by such figures as James Joyce, Franz Kafka, and Virginia Woolf, in literature; Pablo Picasso, Wassily Kandinsky, and Paul Klee, in art; and Arnold Schoenberg and Igor Stravinsky in music. On occasion, it has been applied to the philosophy of the same period, such as that of Friedrich Nietzsche and Martin Heidegger. The denomination has been rarely used in considering mathematics and physics or science, as opposed to "modern," used frequently, but with different periodizations. In mathematics, "modern" tends to refer to the mathematics that had emerged in the nineteenth century, with such figures as Karl Friedrich Gauss, Niels Henrik Abel, and Évariste Galois. In physics it refers to all mathematicalexperimental physics, from Galileo and Descartes on, which uses the mathematics (algebra, analytic geometry, and calculus) developed around the same time. This is fitting because this physics emerged along with and shaped the rise of modernity, making it scientific.

60 A prominent example of using the term modernism in referring to mathematics is Gray's Plato's Ghost: The Modernist Transformation of Mathematics (2008). The book covers developments in modern mathematics that had reached their modernist stage around 1900, the stage that takes the center stage in Against the Day. It characterizes modernism most essentially by the independence from relation to the object of nature, physis, and thus from physics, a feature difficult to deny to mathematical modernism, 
and found, as just noted already in modern mathematics (Gray 20). The book focuses primarily on geometry, with Hilbert's Foundations of Geometry (1999) as the conceptual center, analysis, and on post-Cantorian logical foundations of mathematics, where Hilbert, again, figures prominently. Gray's mathematical modernism covers the same mathematics that figures in Against the Day. Gray marginalizes algebra, where this separation was, again, emerging already during the modern period and became even more pronounced during modernism. Modernism was, in Deleuze and Guattari's language, a line of flight against the day, away from realism, in art, science, and philosophy alike, that ruled the day.

61 It is true that I have here considered radical modernism only in quantum physics, rather than in mathematics, which is, as Badiou noted, not concerned with chance and probability, apart from probability theory. Even the latter is close to physics by virtue of the central role the concept of event plays there. However, the first two key aspects of the RWR view and hence of radical modernism, the irreducibly unthinkable and the irreducibly multiple, are found in modernist mathematics, for example, in view of Gödel's incompleteness theorems (Plotnitsky 2020c). Secondly, modernist mathematics, that of Hilbert spaces, plays a key role in QM and thus in its radically modernist relation to a reality placed beyond thought and thus made RWR, while establishing probabilistic relationships to the effects of RWR, effects defined by chance and, sometimes, correlations, found in quantum phenomena. By the same token, it acquired a purely compositional rather than representational nature. As noted earlier, a representational, realist theory, such as Newton's mechanics, Maxwell's electrodynamics, or Einstein's relativity, is always compositional, too. Heisenberg's way of doing and indeed inventing QM was, however, different. It was akin to and, conceivably, inspired by, the rise of abstract painting, with Wassily Kandinsky and Piet Mondrian. While mathematical modernism is in part defined by its divorce from physics, modernist physics has never divorced itself from mathematics. It gave mathematics an unprecedented significance in physics. It is, in a way, ironic that modernist physics, both relativity (still in a realist way) and quantum theory, depended on mathematics that emerged as a result of this divorce. Heisenberg made QM the most mathematical physical theory ever, because it provided no mechanics for the behavior of quantum objects. The mathematics of $\mathrm{QM}$ was part of the mathematics that took the center stage in Against the Day.

Hence, as I argue here, modernist mathematics in Against the Day becomes a sinthome of the role of modernism, in the history eventually leading to Against the Day itself. I speak of both modernism and radical modernism because radical modernism emerged coextensively with modernism but does not exhaust it, let alone the development of mathematics, physics, and literature and art during that period, not all of which is modernist by any definition. With the same, near mathematical, rigor of language and structure as in Pynchon's other works, Against the Day reflects the complexity of the landscape, artistic, scientific, philosophical, and political, in which modernism emerged, in all these domains, to initiate trajectories, lines of flight, and connections that eventually led to the emergence of the novel, and its own line of flight. I would argue, however, that, whether it depicts or favors such relations in the text, the novel itself, as other Pynchon works, offers us a radically modernist relation to the real, as RWR, historically to the RWR of the time depicted in it and the RWR of our own time. It shows that the rigor of literature can equal the rigor of mathematics, but also assumes the power of chance, along with, I would add, the power of probability. Against the Day 
gives us a chance to relate to this reality, as reality without realism, through a manifold of its effects that the novel brings to us. This manifold, as in all of Pynchon's novels, is incomparably richer than anything that mathematics and science can handle. But literature can.

\section{BIBLIOGRAPHY}

BADIOU, Alain. Being and Event. Translated from the French by Oliver Feltman. New York: Continuum, 2007.

BARBOUR, Julian. The End of Time: The Next Revolution in Physics. Oxford: Oxford University Press, 1999.

BERRESSEM, Hanjo. Eigenvalue: On the Gradual Contraction of Media in Movement. London: Bloomsbury, 2018.

BONCARDO, Robert, and Christian P. GELDER. Mallarmé: Rancière, Milner, Badiou. London: Rowan and Littlefield, 2018.

BOHR, Niels. The Philosophical Writings of Niels Bohr, 3 vols., Woodbridge, CT: Ox Bow Press, 1987.

BORN, Max. The Einstein-Born Letters. Translated from the German by Irene Born. New York, NY: Walker, 2005.

CARROLL, Sean. "From Experience to Metaphor by Way of Imagination." 2005. preposterousuniverse.com/writings/metaphor05/.

Accessed 26 November 2020.

CARROLL, Sean. Something Deeply Hidden: Quantum Worlds and the Emergence of Spacetime. Dutton, NY: 2019.

DELEUZE, Gilles, and Félix GUATTARI. Anti-Oedipus: Capitalism and Schizophrenia. Translated from the French by Robert Hurley, Mark Seem, and Helen Lane. Minneapolis, MN: University of Minnesota Press, 2009.

DELEUZE, Gilles, and Félix GUATTARI. What is Philosophy. Translated from the French by Hugh Tomlinson and Graham Burchell. New York: Columbia University Press, 1994.

DERRIDA, Jacques. Dissemination. Translated from the French by Barbara Johnson. Chicago, IL: University of Chicago Press, 2017.

ENGELHARDT, Nina. Modernism, Fiction, and Mathematics. Edinburgh: Edinburgh University Press, 2019.

FREUD, Sigmund. General Psychological Theory. New York: Collier, 1963.

GRAY, Jeremy. Plato's Ghost: The Modernist Transformation of Mathematics. Princeton, NJ: Princeton University Press, 2008.

HARRIS, Michael. Mathematics without Apologies: Portrait of a Problematic Vocation. Princeton, NJ: Princeton University Press, 2015. 
HILBERT, David, Foundations of Geometry. Translated from the German by Leo Unger and Paul Bernays. La Salle, IL: Open Court, 1999.

JOYCE, James. The Dubliners. New York: Penguin Classics, 1993.

JOYCE, James. Finnegans Wake. Oxford: Oxford University Press, 2012.

KANT, Immanuel. The Critique of Pure Reason. Translated from the German by Paul Gayer and Allen W. Wood. Cambridge: Cambridge University Press, 1997.

LACAN, Jacques. Book XI: The Four Fundamental Concepts of Psychoanalysis, 1964. Ed. Jacques-Alain Miller. Translated from the French by Alan Sheridan. New York: W.W. Norton and Company, 1977.

LACAN, Jacques. Book XXIII: The Sinthome, 1975-1976. Ed. Jacques-Alain Miller. Translated from the French by A.R. Price. Cambridge: Polity, 2016.

LYOTARD, Jean-François. The Postmodern Condition: A Report on Knowledge. Translated from the French by Geoff Bennington and Brian Massumi. Minneapolis, MN: University of Minnesota Press, 1987.

MCHALE, Brian. Postmodern Fiction. New York: Routledge, 1987.

MERMIN, N. David. Boojums All the Way Through. Cambridge: Cambridge University Press, 1990.

PLOTNITSKY, Arkady. The Principles of Quantum Theory, from Planck's Quanta to the Higgs Boson: The Nature of Quantum Reality and the Spirit of Copenhagen. New York: Springer / Nature, 2016.

PLOTNITSKY, Arkady. "'The Unavoidable Interaction Between the Object and the Measuring Instruments': Reality, Probability, and Nonlocality in Quantum Physics," Foundations of Physics, no. 50, 2020, p. 1824-1858 (a).

PLOTNITSKY, Arkady. "Modernist Literature and Modernist Mathematics I: Mathematics and Composition, with Mallarmé, Heisenberg, and Derrida." The Palgrave Handbook of Literature and Mathematics. Eds. Robert Tubbs, Alice Jenkins, and Nina Engelhardt. London: Palgrave, 2020 (b) (forthcoming).

PLOTNITSKY, Arkady. "The Ghost and the Spirit of Pythagoras: The Twentieth and Twenty-First Century Mathematics Between and Beyond Geometry and Algebra." Handbook in the History and Philosophy of Mathematics. Ed. Bharath Sriraman. Berlin: Springer / Nature, 2020 (c).

PLOTNITSKY, Arkady, and KHRENNIKOV, Andrei. "Reality without Realism: On the Ontological and Epistemological Architecture of Quantum Mechanics." Foundations of Physics, vol. 25, no. 10, 2015, p. 1269-1300.

PYNCHON, Thomas. "Entropy.” The Kenyon Review, vol. 22, no. 2, 1960, p. 277-292.

PYNCHON, Thomas. V. 1961. New York: Harper Collins, 2005.

PYNCHON, Thomas. The Crying of Lot 49. New York: Harper and Row, 1966.

PYNCHON, Thomas. Gravity's Rainbow. New York: Bantam, 1973.

PYNCHON, Thomas. Vineland. Boston: Little Brown, 1990.

PYNCHON, Thomas. Mason \& Dixon. New York: Picador, 1997.

PYNCHON, Thomas. Inherent Vice. New York: Penguin, 2009.

PYNCHON, Thomas. Against the Day. New York: Penguin, 2006.

PYNCHON, Thomas. Bleeding Edge. New York: Penguin, 2013. 
SOPHOCLES. The Three Theban Plays: Antigone, Oedipus the King, and Oedipus at Colonus. Translated from the Ancient Greek by Robert Fagles. New York: Penguin Group USA, 1984.

STREHLE, Susan. Fiction in the Quantum Universe. Chapel Hill, NC: University of North Carolina Press, 2000.

WOOLF, Virginia. The Waves. New York: Penguin Classics, 2019.

\section{NOTES}

1. The question of interpretation of $\mathrm{QM}$ has played a central role in the history of $\mathrm{QM}$ and is in fact irreducible in considering the theory. This is why I want to carefully distinguish RWR-type interpretations from other types, some of which are realist, such as the many worlds interpretation, which figures in Pynchon's novels as well. This question is rarely addressed in considering the connections between Pynchon's work and QM, which sometimes leads to confusion concerning QM and its use by Pynchon.

2. I am not claiming that this concept, especially in the strong RWR view, is the same as Lacan's Real. I only claim an affinity with this concept, which is not a fixed but evolving concept in Lacan's oeuvre in any event (both the Imaginary and the Symbolic are more stable). The version of the Real that I especially have in mind is found in Lacan (1977).

3. My engagement with secondary literature is guided by this aim, and is accordingly limited to a few especially relevant works.

4. I have considered both subjects in several previous works (e.g., Plotnitsky 2016, 2020a).

5. Deleuze and Guattari's other defining feature of art, an "affect," while created by a composition, would pertain more strictly to the experience of art rather than that of a mathematical or scientific, or philosophical, composition. In some cases, such compositions, too, could elicit, by their aesthetic qualities, something akin to affects, but this is not a necessary part of their functioning, while it is in the case of artistic compositions. By contrast, the role of composition is, I argue, equally essential in all three domains.

6. It is intriguing that in his discussion of Schrödinger's use of the concept in QM in his recent book on eigenvalue, Hanjo Berressem does not really tackle the role of probability in considering the concept of eigenvalue in $\mathrm{QM}$, and in general only mentions probability in passing, while discussing QM. He addresses chance and probability extensively elsewhere in the book when dealing with classical statistical mechanics and thermodynamics. Berressem bases his discussion of Schrödinger not so much on Schrödinger's original 1926 papers on quantum mechanics, based on this concept, and discussed only briefly (Berressem 2018, 14-16), but on Schrödinger's cat paradox paper just cited, "The Present-Day Situation in Quantum Mechanics" (Schrödinger 1935), which has little to do with and does not even mention "eigenvalue." Nor does it deal with the derivation of QM, well established by that time. As its title suggests, it deals with assessing, in fact critically, the status of QM in 1935, and probability plays a key role in this assessment. Berressem appears to miss or disregard the critical nature of Schrödinger's assessment of QM as "a doctrine born of distress," not the least because of its probabilistic nature, which Schrödinger initially tried to avoid. The probabilistic interpretation of Schrödinger's wave function was given by Max Born. Contrary to Berressem's claim, terms like "probability density" do not appear in Schrödinger's first paper (Berressem 2018, 14). Schrödinger's later concept of expectationcatalog in his cat-paradox paper is most apt, nevertheless, as is much of his analysis of the "doctrine" he repudiates. There also appears to be a confusion in Berressem's discussion between a quantum measurement and a quantum prediction (Berressem, 2018 18). A measurement gives an exact value for a given variable in both classical and quantum physics, while quantum prediction is probabilistic even in the case of a single variable, for which thus only a probabilistic 
expectation-catalog can be formed. Schrödinger is very precise on this. This confusion also leads Berressem to other conceptual imprecisions and errors. Thus, contrary to Berressem (Berressem, 2018 18), an expectation-catalog is equally fully known in both classical and quantum physics; they are just different catalogs. In fact, because in classical mechanics (which is at stake here, rather than classical statistical physics) one can predict all variables ideally exactly, one does not need an expectation-catalog, which is a probabilistic concept and is not used by Schrödinger for classical physics, as Berressem appears to imply. There are no expectations, except with certainty, as we know what is bound to happen in advance, at least ideally. In QM this is not possible even ideally, which is the whole point. In fact, while Berressem notes the importance of Pynchon's use of "eigenvalue" as a proper name in $V$., he does not consider its conceptual role, linked to probability.

7. While there are further nuances, generally the Bayesian view defines probability as a degree of belief concerning a possible occurrence of an individual event on the basis of the relevant information we possess. This makes probabilistic estimates, generally, subjective, although there may be agreement (possibly among a large number of individuals) concerning such estimates.

8. The subject of information, in its postmodern reincarnation, with possible intimations of quantum information theory, returns in Bleeding Edge (Pynchon, 2013).

9. Pynchon eventually wrote two overtly detective novels, Inherent Vice (2009), and Bleeding Edge (2013), which are beyond my scope.

10. Technically, there is the so-called Poisson distribution in the sequence of V2-rocket hits. But each hit is still random, unpredictable, as Roger Mexico explains (Pynchon, 1973 63-64).

11. Gravity's Rainbow was considered in relation to QM by Susan Strehle (2000), from a very different, essentially realist, perspective, that of "continuity" and "parallels," as is indicated in the title of her chapter on Pynchon, "Gravity's Rainbow and the Fiction of Quantum Continuity." As concerns continuity, in QM at least, her main claim that "phenomena remain 'connected' in a sense [...] but connections are looser and more discontinuous than a classical physics could have imagined" (Strehle 29) is, at least, not explained. "Connected" in what sense? What does "more discontinuous connections" mean? In the present, RWR view, there is no way in which quantum phenomena are physically connected: they are irreducibly discrete, quantum, and can only be related to each other by probabilities, the aspect of QM that, I argue here, is important to Pynchon, but not addressed by Strehle. I would also question her claim that, as against "parallels" (important as they may be for the novel) "serial connections imply the rigid and explicit offerings of Newton" (29). The whole point of QM is precisely to show that in the case of quantum phenomena, serial connections do not imply and in fact preclude the strict causality of classical physics, while allowing for probabilities. Pynchon plays with both quantum seriality and parallels, or, again, correlations, and sometimes relates them, something missed by Strehle, who considers uncertainty, but misses probability in Pynchon, along with the possibility of the RWRtype view of the world. Rather than dealing with quantum continuity, Gravity's Rainbow metaphorically mixed quantum discontinuity with a relativity type of continuity of Einstein's nonNewtonian theory of gravity, general relativity. The role of general relativity in Pynchon was helpfully discussed in Engelhardt (2020). There are imprecisions in Strehle's presentation of QM. Thus, she says that "[the] wave function represents the probability that [electrons] are located in a particular place" (Strehle 12). It actually allows one (moreover, not by itself, but by using Born's rule) to predict the probability that an electron will be found within a certain area, but not at any particular place in this area. That is not to deny that the book offers good points concerning the novel, in part because, just as Pynchon's other novels, Gravity's Rainbow exceeds any given understanding of $\mathrm{QM}$ or of its possible connections to the novel. 


\section{ABSTRACTS}

This article discusses the relationships between Thomas Pynchon's novels and the philosophy of chance and probability, especially in connection with quantum theory, which radically redefined our thinking concerning both concepts, and to begin with, the nature of physical reality. The article considers how different scientific theories dealing with chance and probability figure in Pynchon's major novels, which, the article argues, helps us to think more deeply about Pynchon's use of these theories or other mathematical and scientific theories, and about the relationships among literature, philosophy, and mathematics and science in general.

Cet essai s'interroge sur les relations que tissent les romans de Thomas Pynchon avec la philosophie du hasard et de la probabilité, notamment dans son rapport avec la théorie quantique, qui a radicalement redéfini la façon dont nous pensons ces deux concepts, ainsi que, pour commencer, la nature même de la réalité physique. Cet article interroge la présence de diverses théories scientifiques traitant du hasard et de la probabilité dans les principaux romans de Pynchon, et cherche à approfondir la réflexion autour de l'utilisation que fait le romancier de ces théories et d'autres, qu'elles soient mathématiques ou scientifiques. Ce sont donc les articulations entre littérature, philosophie, mathématiques et, plus largement, la science que cet article vise à interroger.

\section{INDEX}

Keywords: causality, chance, multiplicity, probability, quantum theory, reality, reality without realism

Mots-clés: causalité, hasard, multiplicité, probabilité, théorie quantique, réalité, réalité sans réalisme

\section{AUTHOR}

\section{ARKADY PLOTNITSKY}

Purdue University 